\title{
Infections with Zoonotic Trematode Metacercariae in Yellowfin Goby, Acanthogobius flavimanus, from Coastal Areas of Republic of Korea
}

\author{
Woon-Mok Sohn ${ }^{1, *}$, Byoung-Kuk Na1, Shin-Hyeong $\mathrm{Cho}^{2}$, Jung-Won $\mathrm{Ju}^{2}$, Soon-Won Lee ${ }^{3}$, Won-Seok Seok \\ ${ }^{1}$ Department of Parasitology and Tropical Medicine, and Institute of Health Sciences, Gyeongsang National University College of Medicine, \\ Jinju 52727, Korea; 'Division of Vectors and Parasitic Diseases, Centers for Disease Control and Prevention, Osong 28159, Korea; \\ ${ }^{3}$ Infection Disease Intelligence Division, Gangwon Institute of Health and Environment, Chuncheon 24203, Korea
}

\begin{abstract}
To investigate the infection status of zoonotic trematode metacercariae in yellowfin goby, Acanthogobius flavimanus, from coastal areas of the Republic of Korea (Korea), we examined total 344 gobies from 21 localities with an artificial digestion method from 2013 to 2017 . The metacercariae of Stictodora lari were most frequently detected in $45.3 \%$ goby from 7 localities, i.e., Taean-gun (Chungcheongnam-do), Gochang-gun (Jeollabuk-do), Muan-gun, Shinan-gun, Haenam-gun (Jeollanam-do), Hadong-gun and Goseong-gun (Gyeongsangnam-do). Their infection rates were 90.0\%, $66.7 \%, 46.7 \%, 8.0 \%, 3.3 \%, 26.7 \%$, and $86.7 \%$ and intensities were 1,090, 6.2, 1.6 1.0, 2.0, 2.0, and 7.2 metacercariae per fish infected respectively. Heterophyopsis continua metacercariae were found in 38.2\% goby from 6 localities, i.e., Gochang-gun, Muan-gun, Shinan-gun, Gangjin-gun, Boseong-gun (Jeollanam-do) and Goseong-gun, and their intensities were relatively low, 1-21 metacercariae. Stictodora fuscata metacercariae were detected in $61.3 \%$ goby from 4 localities, i.e., Taean-gun, Gochang-gun, Hadong-gun and Goseong-gun. Their infection rates were 90.0\%, 53.3\%, 5.9\%, and $73.3 \%$ and intensities were 1,081, 3.1, 3.0, and 10.2 metacercariae per fish infected respectively. Heterophyes nocens metacercariae were found in $55.0 \%$ goby from Muan-gun and Shinan-gun. Total 3 metacercariae of Isthmiophora hortensis were detected in 2 (8.0\%) gobies from Shinan-gun. Total 15 metacercariae of Centrocestus armatus were detected in 5 gobies (33.3\%) from Gyeongpo-ho (ho means lake) in Gangneung-si, Gangwon-do. The present study suggests that yellowfin goby, $A$. flavimanus, acts as the infection sources of zoonotic intestinal flukes in western and southern coastal areas than in eastern coastal areas of Korea.
\end{abstract}

Key words: Acanthogobius flavimanus, zoonotic trematode, metacercariae, yellowfin goby, coastal area

\section{INTRODUCTION}

Fishborne zoonotic trematodes (FZT) affect the health of peoples in the endemic areas of the world. A lot of trematode species are known to be participated in human infections. Among them, members in family Heterophyidae are very small parasites and clinically important in both aspects of intestinal and extraintestinal cases. More than 30 species in 13 genera have been known to infect human beings all over the world [1-3]. In the Republic of Korea (Korea), 11 species in 8 genera have been reported as human-infecting species of het-

\footnotetext{
- Received 2 April 2018, revised 29 May 2018, accepted 16 June 2018.

*Corresponding author (wmsohn@gnu.ac.kr)

(C) 2018, Korean Society for Parasitology and Tropical Medicine

This is an Open Access article distributed under the terms of the Creative Commons

Attribution Non-Commercial License (http://creativecommons.org/licenses/by-nc/4.0) which permits unrestricted non-commercial use, distribution, and reproduction in any

medium, provided the original work is properly cited.
}

erophyid flukes. Among these, 7 species, Heterophyes nocens, Heterophyopsis continua, Pygidiopsis summa, Stellantchasmus falcatus, Stictodora fuscata, Stictodora lari, and Acanthotrema felis, are infected by the consumption of the raw flesh of brackish water fish [2,4-11]. Lots of residents in the southern and western coastal areas of Korea are infected with these intestinal flukes [12-18]. As the second intermediate host (and/or the source of human infection) of heterophyid flukes, several species of brackish water fish, i.e., Lateolabrax japonicus, Konosirus punctatus, Mugil cephalus, Chelon haematocheilus, Acanthogobius flavimanus, Boleophthalmus pectinirostris, and Scartelaos sp., have been reported in Korea [4-11,19-26].

The studies on the source of human infection for heterophyid flukes were mainly performed in the endemic areas in the western and southern coastal areas of Korea. Most of them were carried out in limited areas and examined small number of fish hosts [6,19-25]. Especially, Seo et al. [19] investigated 
mullet and goby from 14 and 5 localities in the western and southern coastal areas of Korea to know the geographical distribution of Pygidiopsis and Heterophyes metacercariae. Seo et al. [20] also examined mullet, perch and goby from 5, 1, and 3 southwestern coastal areas to survey the infection sources of $H$. continua. Sohn et al. [21] performed an epidemiological survey to know the infection status of heterophyid metacercariae in 4 species of brackish water fish, i.e., shad, perch, mullet and goby, from a local market in Haenam-gun (gun=county), Jeollanam-do (do=province). Kim et al. [23] investigated the heterophyid metacercariae infections in brackish water fishes, i.e., perch, shad, mullet, redlip mullet, and goby, from Jinjuman (man means Bay), Gyeongsangnam-do, Korea. Guk et al. [24] surveyed the infection status of mullet and goby with metacercariae of Heterophyes nocens and Pygidiopsis summa. Sohn et al. [25] performed an epidemiological survey to know the infection status of FZT metacercariae in yellowfin goby collected in Shinan-gun and Muan-gun, Jeollanam-do. Recently, Cho et al. [26] surveyed the infection status of trematode metacercariae in estuarine fishes including yellowfin goby from Muan-gun, Jeollanam-do. Sohn et al. [27] investigated the infection status of $P$. summa metacercariae in mullets from coastal areas of Korea. However, most of studies were performed in limited areas and the number of fish was not enough to evaluate the metacercarial endemicity in each surveyed area. Therefore, we examined goby broadly collected from 21 coastal areas in 3 Korean seas, Yellow Sea, South Sea and East Sea, to know the infection status of zoonotic trematode metacercariae (ZTM).

\section{MATERIALS AND METHODS}

\section{Collection sites of yellowfin goby (Number of goby examined)}

(1) Taean-gun (20), Chungcheongnam-do: Byeongsul-man in Ahnmyeon-eup (eup=town) (latitude: 36.478867; longitude: 126.342750); (2) Buan-gun (15), Jeollabuk-do: Dongjeon-ri (ri=village) in Dongiin-myeon (myeon=township) (35.758721; 126.776704); (3) Gochang-gun (11), Jeollabuk-do: Eupnae-ri in Gochang-eup (35.433979; 126.702451); (4) Gochang-gun (15), Jeollabuk-do: Dongho-ri in Haeri-myeon (35.509479; 126.497485); (5) Muan-gun (15), Jeollanam-do: Haeje-myeon (35.092247; 126.304052); (6) Shinan-gun (25), Jeollanam-do: Aphae-eup (34.841932; 126.363447); (7) Haenam-gun (30), Jeollanam-do: Hwangsan-myeon (34.596476; 126.460790); 8 Gangjin-gun

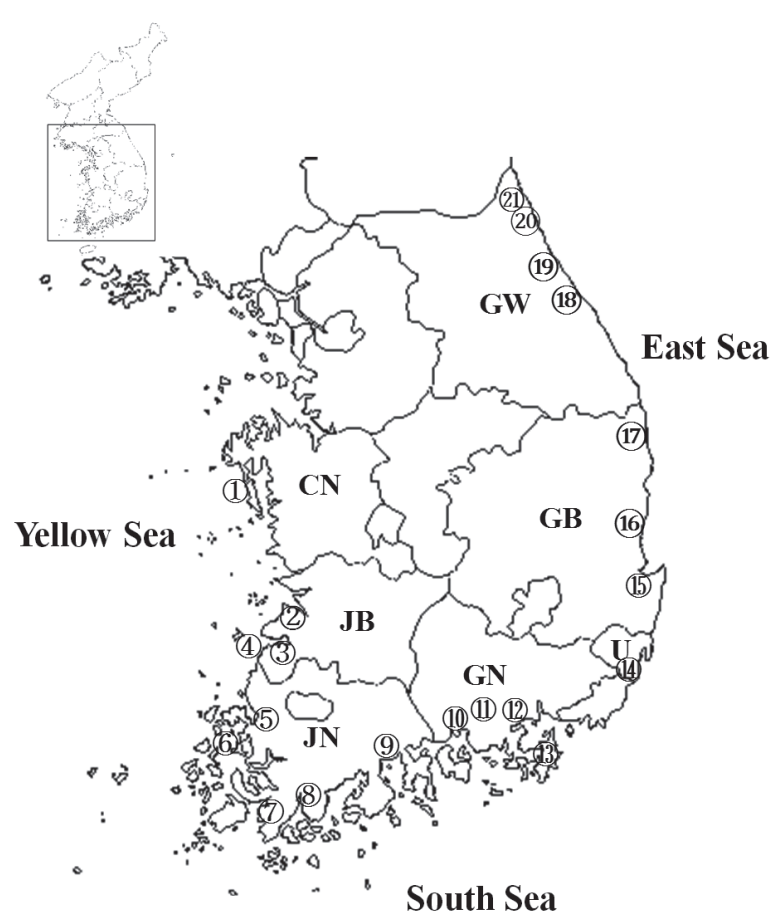

Fig. 1. Surveyed areas in (1)Taean-gun in Chungcheongnam-do (CN); (2) Buan-gun, (3) Gochang-gun (Eupnae-ri in Gochang-eup) and (4) Gochang-gun (Dongho-ri in Haeri-myeon) in Jeollabuk-do (JB); (5)Muan-gun, (6) Shinan-gun, (7) Haenam-gun, (8) Gangjin-gun and (9) Boseong-gun in Jeollanam-do (JN); (10)Hadong-gun, (11) Sacheon-si, (12) Goseong-gun and (13) Geoje-si in Gyeongsangnam-do (GN); (14)Ulsan Metropolitan City (U), (15)Pohang-si, (16) Yeongdeokgun, and (17) Uljin-gun in Gyeongsangbuk-do (GB); (18) Gangneungsi, (19) Yangyang-gun, (20) Goseong-gun (Songjiho in Jukwang-myeon), and (21) Goseong-gun (Hwajinpoho in Geojin-eup) in Gangwon-do (GW).

(22), Jeollanam-do: Daegu-myeon (34.500880; 126.792037); (9) Boseong-gun (16), Jeollanam-do: Beolgyo-eup (34.830308; 127.370214); (10) Hadong-gun (15), Gyeongsangnam-do: Jingyomyeon (35.009910; 127.918501); (11) Sacheon-si (25), Gyeongsangnam-do: Gonyang-cheon (cheon means stream) in Gonyang-myeon (35.049422; 127.975090); (12) Goseong-gun (30), Gyeongsangnam-do: Baedun-ri in Hoehwa-myeon (35.048684; 128.372615); (13) Geoje-si (10), Gyeongsangnam-do: Dundeokcheon in Dundeok-myeon $(34.838177 ; 128.508674)$ (14) Ulsan Metropolitan City (1): Taehwa-gang (gang means river) in Junggu (35.547438; 129.297372); (5) Pohang-si (15), Gyeongsangbukdo: Hyeongsan-gang in Yeonil-eup (36.003818; 129.332359); (16) Yeongdeok-gun (2), Gyeongsangbuk-do: Osip-cheon in Ganggumyeon (36.379421; 129.376851); (17) Uljin-gun (1), Gyeongsangbuk-do: Wangpi-cheon in Uljin-eup (36.965826; 129.394991); (18) Gangneung-si (26), Gangwon-do: Gyeongpo-ho (ho means 
Table 1. Infection status of trematode metacercariae in yellowfin goby, Acanthogobius flavimanus, from western coastal areas of Korea

\begin{tabular}{|c|c|c|c|}
\hline \multirow{2}{*}{ Locality (No. goby examined) Trematode } & \multirow{2}{*}{ No. (\%) of fish infected } & \multicolumn{2}{|c|}{ No. of metacercariae detected } \\
\hline & & Range & Average \\
\hline \multicolumn{4}{|l|}{ (1) Taean-gun, Chungcheongnam-do (20) } \\
\hline Stictodora lari & $18(90.0)$ & $2-4,130$ & 1,090 \\
\hline Stictodora fuscata & $18(90.0)$ & $7-2,250$ & 1,081 \\
\hline \multicolumn{4}{|l|}{ (4) Gochang-gun, Jeollabuk-do (15) } \\
\hline Stictodora lari & $10(66.7)$ & $1-10$ & 6.2 \\
\hline Stictodora fuscata & 8 (53.3) & $1-9$ & 3.1 \\
\hline Heterophyopsis continua & $2(13.3)$ & $1-2$ & 1.5 \\
\hline \multicolumn{4}{|l|}{ (5) Muan-gun, Jeollanam-do (15) } \\
\hline Heterophyopsis continua & $14(93.3)$ & $1-78$ & 21.0 \\
\hline Stictodora lari & $7(46.7)$ & $1-3$ & 1.6 \\
\hline Heterophyes nocens & $4(26.7)$ & $1-4$ & 2.5 \\
\hline \multicolumn{4}{|l|}{ (6) Shinan-gun, Jeollanam-do (25) } \\
\hline Heterophyes nocens & $18(72.0)$ & & \\
\hline Heterophyopsis continua & $1(4.0)$ & - & 1.0 \\
\hline Stictodora lari & $2(8.0)$ & - & 1.0 \\
\hline Isthmiophora hortensis & $2(8.0)$ & $1-2$ & 1.5 \\
\hline
\end{tabular}

Table 2. Infection status of trematode metacercariae in yellowfin goby, Acanthogobius flavimanus, from southern coastal areas of Korea

\begin{tabular}{|c|c|c|c|}
\hline \multirow{2}{*}{ Locality (No. goby examined) Trematode } & \multirow{2}{*}{ No. (\%) of fish infected } & \multicolumn{2}{|c|}{ No. of metacercariae detected } \\
\hline & & Range & Average \\
\hline $\begin{array}{l}\text { (7) Haenam-gun, Jeollanam-do (30) } \\
\text { Stictodora lari }\end{array}$ & $1(3.3)$ & - & 2.0 \\
\hline $\begin{array}{l}\text { (8) Gangjin-gun, Jeollanam-do (22) } \\
\text { Heterophyopsis continua }\end{array}$ & $2(9.1)$ & $1-3$ & 2.0 \\
\hline $\begin{array}{l}\text { (9) Boseong-gun, Jeollanam-do (16) } \\
\text { Heterophyopsis continua }\end{array}$ & $14(87.5)$ & $1-48$ & 8.6 \\
\hline $\begin{array}{l}\text { (10) Hadong-gun, Gyeongsangnam-do (15) } \\
\text { Stictodora lari } \\
\text { Stictodora fuscata }\end{array}$ & $\begin{array}{l}4(26.7) \\
1(5.9)\end{array}$ & $\begin{array}{c}1-4 \\
-\end{array}$ & $\begin{array}{l}2.0 \\
3.0\end{array}$ \\
\hline $\begin{array}{l}\text { (12) Goseong-gun, Gyeongsangnam-do (30) } \\
\text { Stictodora lari } \\
\text { Stictodora fuscata } \\
\text { Heterophyopsis continua }\end{array}$ & $\begin{array}{l}26(86.7) \\
22(73.3) \\
14(46.7)\end{array}$ & $\begin{array}{l}1-52 \\
1-45 \\
1-15\end{array}$ & $\begin{array}{r}7.2 \\
10.2 \\
3.5\end{array}$ \\
\hline
\end{tabular}

lake) in Woonjeong-dong (37.797481; 128.911507); (19) Yangyanggun (16), Gangwon-do: Mae-ho in Hyeonnam-myeon (37.949 674; 128.774899); (20) Goseong-gun (11), Gangwon-do: Songiho in Jukwang-myeon (38.335426; 128.51339); (21) Goseonggun (23), Gangwon-do: Hwajinpo-ho in Geojin-eup (38.466 792; 128.442357) (Fig. 1).

\section{Examination of fish}

Total 344 gobies were collected in the above 21 coastal areas for 5 years (2013: (1)-(6); 2014: (7)-(13), (18), (21); 2015: (14)-(17), (20); 2017: (18)-(21)). All collected goby were transferred to our laboratory (in Department of Parasitology and Tropical Medicine, Gyeongsang National University College of Medicine, Jinju, Korea) with ice, and examined by the artificial digestion method. Each fish was finely ground with a mortar or grinder, the ground fish meat was mixed well with artificial gastric juice, and the mixture was incubated at $36^{\circ} \mathrm{C}$ for $2 \mathrm{hr}$. The digested material was filtered with $1 \times 1 \mathrm{~mm}$ of mesh and washed with $0.85 \%$ saline untill the supernatant is clear. Trematode metacercariae were collected from sediments under a stereomicroscope and categorized according to the size and morphological characteristics. Infection rates (\%) and intensities (No. of ZTM per fish infected) were then calculated.

\section{RESULTS}

\section{Infection status of ZTM in yellowfin goby from western coastal areas}

No metacercariae were detected in goby from (2) Buan-gun and (3) Gochang-gun. In goby from (1) Taean-gun, 2 species of 
Stictodora, S. lari and S. fuscata, metacercariae were commonly detected in 18 (90.0\%) fish, and their intensities were 1,090 and 1,081 per fish infected. Total 3 species of heterophyid, i.e., S. lari, S. fuscata, and H. continua, metacercariae were found in $66.7 \%, 53.3 \%$, and $13.3 \%$ goby from (4) Gochang-gun, and their intensities were 6.2, 3.1, and 1.5 per fish infected respectively. In goby from (5) Muan-gun, 3 species of heterophyid, i.e., $H$. continua, $S$. lari, and $H$. nocens, metacercariae were found in $93.3 \%, 46.7 \%$, and $26.7 \%$ fish, and their intensities were 21.0, 1.6, and 2.5 per fish infected respectively. Total 4 species, i.e., H. nocens, H. continua, S. lari, and Isthmiophora hortensis, of ZTM were found in $72.0 \%, 4.0 \%, 8.0 \%$, and $8.0 \%$ goby from (6) Shinan-gun, and their intensities were 21.1, 1.0, 1.0, and 1.5 per fish infected respectively. Infection status of ZTM in goby from western coastal areas is detailedly designated in Table 1.

\section{Infection status of ZTM in yellowfin goby from southern coastal areas}

No metacercariae were detected in goby from (11) Sacheon-si and (13) Geoje-si. Total 2 metacercariae of $S$. lari were found in only one goby (3.3\%) from (7) Haenam-gun. In goby from (8) Gangiin-gun, and (9) Boseong-gun, only H. continua metacercariae were detected in $9.1 \%$ and $87.5 \%$ fish, and their intensities were 2.0 and 8.6 per fish infected each. Two species of Stictodora, S. lari, and S. fuscata, metacercariae were found in 26.7\% and 5.9\% goby from (10) Hadong-gun, their intensities were 2.0 and 3.0 per fish infected. In goby from (12) Goseonggun, 3 species of heterophyid, i.e., S. lari, S. fuscata, and H. continua, metacercariae were detected in $86.7 \%, 73.3 \%$, and $46.7 \%$ fish, and their intensities were 7.2, 10.2, and 3.5 per fish infected respectively. Infection status of ZTM in goby from southern coastal areas is shown in Table 2.

\section{Infection status of ZTM in yellowfin goby from eastern coastal areas}

No ZTM were detected in all goby from eastern coastal areas except those from (18) Gyeongpo-ho in Gangneung-si, Gangwon-do. Total 15 metacercariae of Centrocestus armatus were detected in 5 gobies (33.3\%) from (18) Gyeongpo-ho.

\section{DISCUSSION}

By the present study, It was confirmed that ZTM are mainly prevalent in goby from the western and southern coastal areas of Korea. No ZTM were detected in total 95 gobies from the eastern coastal areas except for 5 ones from Gyeongpo-ho in Gangneung-si, Gangwon-do. Total 4 species of heterophyid flukes, i.e., H. nocens, H. continua, S. lari, and S. fuscata, and 1 species of echinostomatid fluke, I. hortensis, metacercariae were detected in the goby from the western coastal areas. Among these, $H$. nocens metacercariae were prevalent in the goby from Shinan-gun, $H$. continua metacercariae were relatively prevalent in the goby from Muan-gun, Jeollanam-do, and S. lari, and S. fuscata metacercariae were highly prevalent in the goby from Taean-gun, Chungcheongnam-do. In the goby from the southern coastal areas, 3 species of heterophyid flukes, i.e., $H$. continua, S. lari, and S. fuscata, metacercariae were detected. However, their endemicities were not so high. In the eastern coastal areas, only Centrocestus armatus metacercariae were found in 5 gobies from Gyeongpo-ho in Gangneung-si, Gangwon-do. Therefore, we are able to know that ZTM are more prevalent in the goby from the western coastal areas than from southern coastal areas, and they are very rarely infected in the goby from the eastern coastal areas.

The yellowfin goby, A. flavimanus, is known to be the suitable fish host of 6 species of heterophyid flukes, i.e., H. nocens, H. continua, P. summa, S. fuscata, S. lari, and A. felis, and 1 species of echinostome, I. hortensis, in Korea [8-10,20-25]. In the present study, 5 species, i.e., H. nocens, $H$. continua, S. lari, $S$. fuscata, and I. hortensis, of ZTM were detected, and their infection rates and intensities were more or less different by the species of ZTM and surveyed areas. Cho et al. [26] detected 3 species, i.e., H. continua, S. lari, and A. felis, of ZTM in the goby from Muan-gun, Jeollanam-do. Their each prevalences and intensities were relatively high. Sohn et al. [25] detected more than 5 species, i.e., H. nocens, H. continua, P. summa, Stictodora spp., and I. hortensis, of ZTM in the goby from Shinan-gun and Muan-gun, Jeollanam-do. Their each prevalences and intensities were much different from those of the same regions in this study. Sohn et al. [21] found 3 species, i.e., H. nocens, H. continua, and S. fuscata, of ZTM in the goby from Haenam-gun in Jeollanam-do. In this study, only $2 \mathrm{~S}$. lari metacercariae were detected in only 1 out of 30 gobies from Haenam-gun. Kim et al. [23] detected more than 2 species, Stictodora spp. and $H$. continua, of ZTM in the goby from Jinju-man. However, we found no ZTM in 25 gobies from Gonyang-cheon in Sacheonsi, Gyeongsangnam-do.

A species of heterophyid fluke, H. nocens, is known to be the prevalent species in the residents of western and southern coastal areas, i.e., Okgu-gun and Buan-gun in Jeollabuk-do, 
Muan-gun, Shinan-gun, Gangjin-gun, Goheung-gun, Haenamgun and Yeongam-gun in Jeollanam-do, Namhae-gun, Geojesi and Sacheon-si in Gyeongsangnam-do [12-16,18]. The yellowfin goby, A. flavimanus, act as one of the infection sources of this fluke in these endemic areas. Sohn et al. [25] reported $6.7 \%$ and $100 \%$ prevalences and 2 and 153 average intensities of $H$. nocens metacercariae in goby from Muan-gun and Shinan-gun, Jeollanam-do. Guk et al. [24] reported 20.0\% and $40.0 \%$ prevalences and each 2 average metacercarial intensities in goby from Muan-gun in Jeollanam-do and Seocheon-gun in Chungcheongnam-do. Sohn et al. [21] also reported 10\% prevalence and 32 average intensity of $H$. nocens metacercariae in goby from Haenam-gun in Jeollanam-do. In the present study, H. nocens metacercariae were detected in the goby from Muan-gun and Shinan-gun in Jeollanam-do only, their prevalences were $26.7 \%$ and $72.0 \%$ and intensities were 2.5 and 21.1 per fish infected. According to the results in previous and present studies, $H$. nocens metacercariae are most prevalent in the goby from Shinan-gun in Jeollanam-do, Korea.

Human infection cases of $H$. continua have been sporadically reported in the western and southern coastal areas, i.e., Buan-gun in Jeollabuk-do, Shinan-gun, Muan-gun, Gangjingun, Haenam-gun and Yeongam-gun in Jeollanam-do, Sacheon-si in Gyeongsangnam-do, of Korea $[12,14,16,20,28]$. Variety of fish species, i.e., L. japonicus, A. flavimanus, C. punctatus, M. cephalus, Conger myriaster, Plecoglossus altivelis, B. pectinirostris, and Scartelaos sp. were reported as the second intermediate hosts of this heterophyid fluke in Korea $[4,11,20,21$, $25,26,29]$. Cho et al. [26] detected $45.8 \mathrm{H}$. continua metacercariae per fish infected in 27 (79.4\%) goby from Muan-gun in Jeollanam-do. Sohn et al. [25] found 23.3 and $19.9 \mathrm{H}$. continua metacercariae per fish infected in each $15(100 \%)$ goby from Muan-gun and Shinan-gun in Jeollanam-do. Kim et al. [23] found total $25 \mathrm{H}$. continua metacercariae in 9 (25.7\%) out of 35 gobies from Jinju-man in Gyeongsangnam-do. Sohn et al. [21] also detected total $96 \mathrm{H}$. continua metacercariae in 3 (10\%) out of 30 gobies from Haenam-gun in Jeollanam-do. In the present study, H. continua metacercariae were detected in goby from Gochang-gun in Jeollabuk-do, Muan-gun, Shinan-gun, Ganjin-gun and Boseong-gun in Jeollanam-do, and Goseong-gun in Gyeongsangnam-do, their prevalences were 4.0-93.3\% (38.2\% in average) and intensities were 1.0-21.0 (10 in average) per fish infected. Based on the results in previous and present studies, we can know that $H$. continua metacercariae are more or less prevalent in goby from Muan-gun in Jeolla- nam-do, but their endemicities were relatively low in the goby from other areas in Korea.

In the present study, S. lari metacercariae were found in goby from 7 surveyed areas, i.e., Taean-gun in Chungcheongnam-do, Gochang-gun in Jeollabuk-do, Muan-gun, Shinangun and Haenam-gun in Jeollanam-do, Hadong-gun and Goseong-gun in Gyeongsangnam-do. Their endemicities were not so high except for that in Taean-gun, Chungcheongnamdo. On the other hand, human infections with this fluke were reported in residents of 4 southwestern coastal villages in Gangjin-gun, Shinan-gun and Muan-gun in Jeollanam-do and Sacheon-si in Gyeongsangnam-do, Korea $[2,16,18]$. Metacercarial infections in goby were also reported in the southwestern coasts, i.e., Muan-gun in Jeollanam-do and Sacheon-si in Gyeongsangnam-do $[8,26]$. The metacercariae of $S$. fuscata were detected in the goby from 4 surveyed areas, Taean-gun in Chungcheongnam-do, Gochang-gun in Jeollabuk-do, Hadong-gun and Goseong-gun in Gyeongsangnam-do, in this study. Their endemicities were relatively low except for that in Taean-gun, Chungcheongnam-do. Human infections with this fluke were sporadically reported in peoples residing in the southwestern coastal areas of Korea $[2,17,12-14,18]$. Four species of brackish water fish, i.e., A. flavimanus, B. pectinirostris, $M$. cephalus, and $C$. haematocheilus, were known to be the second intermediate hosts in Korea $[11,21,26]$. Sohn et al. [21] detected total 9 S. fuscata metacercariae in 3 (10\%) gobies from Haenam-gun, Jeollanam-do.

Sohn et al. [25], previously reported that the yellowfin goby, A. flavimanus, is a second intermediate host for I. hortensis in Korea. They detected total $8 \mathrm{I}$. hortensis metacercariae in 2 out of 14 gobies from Jido-myeon in Shinan-gun, Jeollanam-do. We also found total 3 I. hortensis metacercariae in 2 out of 25 gobies from Shinan-gun in Jeollanam-do. In the present study, it is first confirmed that the yellowfin goby, A. flavimanus, acts as the second intermediate host of $C$. armatus in Korea. Total 15 C. armatus metacercariae were detected in 5 (33.3\%) gobies from Gyeongpo-ho in Gangneung-si, Gangwon-do. Conclusively the present study suggests that those who consume raw goby from western and southern coastal areas of Korea are at high risk of getting infected with heterophyid flukes.

\section{ACKNOWLEDGMENTS}

This study was supported by an Anti-Communicable Diseases Control Program, 2013 (Studies on the biological re- 
sources of human infecting trematodes and their larval infections in intermediate hosts), 2014 (Investigation of fishborne parasites and acquisition of their biological resources in the southern regions of Korea) and 2015 (Investigation of fishborne parasites and acquisition of their biological resources in the eastern regions of Korea) of National Research Institute of Health (NRIH), Korea Centers for Disease Control and Prevention (KCDCP). We thank Jung-A Kim and Hee-Ju Kim, Department of Parasitology and Tropical Medicine, Gyeongsang National University College of Medicine, Jinju, Korea, for their help in fish examinations.

\section{CONFLICT OF INTEREST}

The authors have no conflicts of interest concerning the work reported in this paper.

\section{REFERENCES}

1. Chai JY. Iintestinal flukes. Food-Borne Parasitic Zoonoses: Fish and Plant-Borne Parasites. In Murrell KD, Fried B eds. New York, USA. Springer. 2007, pp 53-115.

2. Chai JY, Lee SH. Food-borne intestinal trematode infections in the Republic of Korea. Parasitol Int 2002; 51: 129-154.

3. Africa CM, de Leon W, Garcia EY. Visceral complications in intestinal heterophyidiasis of man. Acta Medica Philippina Monographic Series 1940; 1: 1-325.

4. Chun SK. A study on some trematodes whose intermediate hosts are brackish water fish. (I) The life history of Heterophyes continus, the intermediate host of which is Lateolabrax japonicus. Bull Pusan Fish Coll 1960; 3: 40-44 (in Korean).

5. Chun SK. A study on some trematodes whose intermediate host are brackish water fish. (II) The life history of Pygidiopsis summa, the intermediate host of which is Mugil cephalus. Bull Pusan Fish Coll 1963; 5: 1-5 (in Korean).

6. Seo BS, Cho SY, Chai JY, Hong ST. Studies on intestinal trematodes in Korea II. Identification of the metacercariae of Heterophyes heterophyes nocens in mullets of three southern coastal areas. Seoul J Med 1980; 21: 30-38.

7. Chai JY, Sohn WM. Identification of Stellantchasmus falcatus metacercariae encysted in mullets in Korea. Korean J Parasitol 1988; 26: 65-68.

8. Chai JY, Park SK, Hong SJ, Choi MH, Lee SH. Identification of Stictodora lari (Heterophyidae) metacercariae encysted in the brackish water fish, Acanthogobius flavimanus. Korean J Parasitol 1989; 27: 253-259.

9. Sohn WM, Chai JY, Lee SH. Stictodora fuscatum (Heterophyidae) metacercariae encysted in gobies, Acanthogobius flavimanus. Korean J Parasitol 1994; 32: 143-147.

10. Sohn WM, Han ET, Seo M, Chai JY. Identification of Acanthotre- ma felis (Digenea: Heterophyidae) metacercariae encysted in the brackish water fish Acanthogobius flavimanus. Korean J Parasitol 2003; 41: 101-105.

11. Sohn WM, Kim JA, Song HJ. Two species of goby, Boleophthalmus pectinirostris and Scartelaos sp., as the new second intermediate host of heterophyid flukes in Korea. Korean J Parasitol 2005; 43: 161-164.

12. Chai JY, Kim IM, Seo M, Guk SM, Kim JL, Sohn WM, Lee SH. A new endemic focus of Heterophyes nocens, Pygidiopsis summa, and other intestinal flukes in a coastal area of Muan-gun, Chollanam-do. Korean J Parasitol 1997; 35: 233-238.

13. Chai JY, Nam HK, Kook J, Lee SH. The first discovery of an endemic focus of Heterophyes nocens (Heterophyidae) infection in Korea. Korean J Parasitol 1994; 32: 157-161.

14. Chai JY, Song TE, Han ET, Guk SM, Park YK, Choi MH, Lee SH. Two endemic foci of heterophyids and other intestinal fluke infections in southern and western coastal areas in Korea. Korean J Parasitol 1998; 36: 155-161.

15. Chai JY, Park JH, Han ET, Shin EH, Kim JL, Guk SM, Hong KS, Lee SH, Rim HJ. Prevalence of Heterophyes nocens and Pygydiopsis summa infections among residents of the western and southern coastal islands of the Republic of Korea. Am J Trop Med Hyg 2004; 71: 617-622.

16. Park JH, Kim JL, Shin EH, Guk SM, Park YK, Chai JY. A new endemic focus of Heterophyes nocens and other heterophyid infections in a coastal area of Gangjin-gun, Jeollanam-do. Korean J Parasitol 2007; 45: 33-38.

17. Chai JY, Hong SJ, Lee SH, Seo BS. Stictodora sp. (Trematoda: Heterophyidae) recovered from a man in Korea. Korean J Parasitol 1988; 26: 127-132.

18. Cho SH, Cho PY, Lee DM, Kim TS, Kim IS, Hwang EJ, Na BK, Sohn WM. Epidemiological survey on the infection of intestinal flukes in residents of Muan-gun, Jeollanam-do, the Republic of Korea. Korean J Parasitol 2010; 48: 133-138.

19. Seo BS, Hong ST, Chai JY, Cho SY. Studies on intestinal trematodes in Korea IV. Geographical distribution of Pygidiopsis and Heterophyes metacercariae. Seoul J Med 1981; 22: 236-242.

20. Seo BS, Lee SH, Chai JY, Hong SJ. Studies on intestinal trematodes in Korea XIII. Two cases of natural human infection by Heterophyopsis continua and the status of metacercarial infection in brackish water fishes. Korean J Parasitol 1984; 22: 51-60.

21. Sohn WM, Han GG, Kho WG, Chai JY, Lee SH. Infection status with the metacercariae of heterophyid flukes in the brackish water fish from Haenam-gun, Chollanam-do, Korea. Korean J Parasitol 1994; 32: 163-169 (in Korean).

22. Sohn WM, Moon BC. Infection status with the metacercariae of heterophyid trematode in mullet and goby collected from western coastal areas of Cholla-do, Korea. J Biomed Lab Sci 2001; 7: 31-37.

23. Kim DG, Kim TS, Cho SH, Song HJ, Sohn WM. Heterophyid metacercarial infections in brackish water fishes from Jinju-man (Bay), Kyongsangnam-do, Korea. Korean J Parasitol 2006; 44: 7-13. 
24. Guk SM, Shin EH, Kim JL, Sohn WM, Hong KS, Yoon CH, Lee SH, Rim HJ, Chai JY. A survey of Heterophyes nocens and Pygidiopsis summa metacercariae in mullets and gobies along the coastal areas of the Republic of Korea. Korean J Parasitol 2007; 45: 205211.

25. Sohn WM, Na BK, Cho SH. Echinostoma hortense and heterophyid metacercariae encysted in yellowfin goby, Acanthogobius flavimanus, from Shinan-gun and Muan-gun (Jeollanam-do), Korea. Korean J Parasitol 2009; 47: 307-310.

26. Cho SH, Kim IS, Hwang EJ, Kim TS, Na BK, Sohn WM. Infection status of estuarine fish and oysters with intestinal fluke metacercariae in Muan-gun, Jeollanam-do, Korea. Korean J Parasitol
2012; 50: 215-220.

27. Sohn WM, Na BK, Cho SH, Lee WJ, Park MY, Lee SW, Choi SB, Huh BN, Seok WS. Pygidiopsis summa (Digenea: Heterophyidae): status of metacercarial infection in mullets from coastal areas in the Republic of Korea. Korean J Parasitol 2016; 54: 497-502.

28. Hong SJ, Chang CK, Lee DH, Woo HC. One human case of natural infection by Heterophyopsis continua and three other species of intestinal trematodes. Korean J Parasitol 1996; 34: 87-90.

29. Cho SY, Kim SI. Plecoglossus altivelis as a new fish intermediate host of Heterophyopsis continua. Korean J Parasitol 1985; 23: 173174. 
